\title{
PENGGUNAAN LIMBAH POLIETILEN DENSITAS TINGGI SEBAGAI PENGUBAH BITUMEN DALAM CAMPURAN BETON ASPAL
}

\author{
Heru Prasetyo ${ }^{1}$, Sugeng Dwi Hartantyo ${ }^{2}$, Herlan Pratikto ${ }^{3}$, Heri Wahyudiono ${ }^{4}$ \\ ${ }^{1,2}$ Fakultas Teknik Universitas Islam Lamongan \\ ${ }^{3,4}$ Fakultas Teknik Universitas Kadiri
}

Email: Heruprash@gmail.com, sugeng.dwih@gmail.com, herlan_pratikto@unik-kediri.ac.id, heri_wahyudiono@unik-kediri.ac.id

\begin{abstract}
The purpose of this study is to investigate the possibility of using various plastic wastes containing High Density Polyethylene as an additive polymer for asphalt concrete. It was investigated that the effect of HDPE modified binders was obtained by various mixing times, mixing temperatures and HDPE content on Marshall Stability, flow, and Marshall Quotient. The binder used in Hot Asphalt Mixing (HMA) was prepared by mixing HDPE in 4-6\% and 8\% (based on optimal asphalt content weight) and AC-20 at temperatures of 145-155 and $165 \mathrm{jC}$ and 5-15 and 30 minutes of mixing time. Asphalt concrete modified by HDPE is quite large in increasing Marshall Stability and Marshall Quotient values (resistance to deformation). Four percent HDPE, $165 j \mathrm{C}$ of mixing temperature and 30 minutes of mixing time were determined as optimum conditions for Marshall Stability, flow and Marshall Quotient (MQ). MQ increased by 50\% compared to the control mixture. It can be said that modified HDPE bitumen binder waste provides better resistance to permanent deformation due to high stability and high Marshall Quotient and contributes to recirculation of plastic waste as well as to environmental protection. D 2003 Elsevier BV All rights reserved.
\end{abstract}

Keywords: Asphalt Concrete, Waste Material, Modified Bitumen, Marshall Stability

\begin{abstract}
Abstrak
Tujuan dari penelitian ini adalah untuk menyelidiki kemungkinan penggunaan berbagai limbah plastik yang mengandung High Density Polyethylene sebagai polimer aditif untuk beton aspal. Itu diselidiki bahwa pengaruh pengikat dimodifikasi HDPE diperoleh dengan berbagai waktu pencampuran, pencampuran suhu dan konten HDPE pada Stabilitas, aliran, dan Marshall Quotient (Rasio Stabilitas terhadap Aliran) Marshall. Pengikat yang digunakan dalam Hot Mix Aspal (HMA) disiapkan dengan mencampurkan HDPE dalam 4-6\% dan 8\% (berdasarkan berat konten aspal optimal) dan AC-20 pada suhu 145-155 dan $165 \mathrm{jC}$ dan 5-15 dan 30 menit waktu pencampuran. Beton aspal hasil modifikasi HDPE cukup besar peningkatan nilai Stabilitas (kekuatan) Marshall dan nilai Marshall Quotient (resistensi terhadap deformasi). HDPE empat persen, $165 j \mathrm{C}$ dari suhu pencampuran dan 30 menit waktu pencampuran ditentukan sebagai kondisi optimum untuk Stabilitas Marshall, aliran dan Marshall Quotient(MQ). MQ meningkat 50\% dibandingkan dengan campuran kontrol. Dapat dikatakan bahwa limbah pengikat bitumen HDPE yang dimodifikasi memberikan ketahanan yang lebih baik terhadap deformasi permanen karena stabilitas tinggi dan Marshall Quotient yang tinggi dan berkontribusi terhadap resirkulasi limbah plastik sebagai juga untuk perlindungan lingkungan. D 2003 Elsevier BV Semua hak dilindungi undang-undang.
\end{abstract}

Kata Kunci: Beton Aspal, Bahan Limbah, Bitumen Yang Dimodifikasi, Stabilitas Marshall 


\section{PENDAHULUAN}

Dalam beberapa tahun terakhir, berbagai bahan limbah dihasilkan dari operasi manufaktur, industri jasa dan rumah berlaku di Indonesia. Masalah, bagaimanapun, dialami karena untuk kapasitas TPA yang tidak mencukupi dan keterbatasan alat didaur ulang. Pemanfaatan limbah sangat menarik alternatif untuk pembuangan dalam biaya dan potensi pembuangan itu masalah polusi berkurang atau bahkan dihilangkan bersama dengan pencapaian konservasi sumber daya. Sebaliknya, biaya konstruksi jalan raya baru-baru ini menunjukkan kenaikan di Indonesia. Sudah diketahui bahwa penambahan keduanya, beberapa bahan limbah dan tertentu polimer, untuk pengikat aspal dapat meningkatkan kinerja beton aspal. Polyethylene juga telah ditemukan sebagai salah satu aditif polimer yang paling efektif. Di Indonesia, ada sekitar juta ton bahan yang mengandung HDPE. Mungkin sangat mungkin bahwa bahan limbah HDPE dari keduanya dapat mempengaruhi sifat rekayasa awal perkerasan HMA dan meningkatkan umur layanannya. Namun, karena kondisi pencampuran untuk aspal dan polimer memiliki efek yang cukup besar pada perilaku polimer bitumen yang dimodifikasi, harus ditentukan sebagai yang paling banyak kondisi pencampuran yang cocok untuk aspal dan polimer. Untuk tujuan ini, bitumen yang dimodifikasi diperoleh dengan mencampurkan bitumen dan pengubah pada suhu dan waktu tertentu. Jika waktu dan suhu pencampuran yang konsisten tidak disediakan untuk campuran pengubah bitumen, yang dimodifikasi tidak dapat menunjukkan kinerja in situ yang baik, karenanya kegagalan prematur akan terjadi. Selain itu, tenda juga merupakan faktor penting yang mempengaruhi kinerja dari beton aspal yang dimodifikasi polimer. Karena itu, ada waktu pencampuran yang disarankan, pencampuran konten suhu dan pengubah untuk semua polimer dengan merek dagang. Stabilitas perkerasan HMA, yang paling penting milik campuran aspal dalam perjalanan pakai desain, adalah kemampuannya untuk menahan dorongan dan alur di bawah lalu lintas. Karena itu, stabilitas harus cukup tinggi untuk ditangani

Tabel 1: Hasil tes dilakukan pada semen aspal

\begin{tabular}{llc}
\hline Penetration, $25{ }^{\circ} \mathrm{C}, 100 \mathrm{~g}, 5 \mathrm{~s}(1 / 10 \mathrm{~mm})$ & ASTM D5 & 67 \\
Specific gravity $\left(\mathrm{kN} / \mathrm{m}^{3}\right)$ & ASTM D70 & 1.047 \\
Flash point $\left({ }^{\circ} \mathrm{C}\right)$ & ASTM D92 & 215 \\
Ductility, $25{ }^{\circ} \mathrm{C}, 5 \mathrm{~cm} / \mathrm{min}$ & ASTM D113 & +100 \\
Softening point $\left({ }^{\circ} \mathrm{C}\right)$ & ASTM D36 & 56 \\
\hline
\end{tabular}

lalu lintas memadai, tetapi tidak lebih tinggi dari kondisi lalu lintas yg dibutuhkan. Kurangnya stabilitas dalam campuran aspal menyebabkan terurai dan mengalirnya permukaan jalan. Flow 
adalah kemampuan perkerasan HMA untuk menyesuaikan dengan pemukiman bertahap dan gerakan di tanah dasar tanpa retak. Aliran dapat dianggap sebagai properti yang berlawanan dengan stabilitas, menentukan perilaku yang dapat dibalik dari jalur pemakaian di bawah beban lalu lintas dan mempengaruhi sifat plastik dan elastis dari beton aspal. Hasil bagi Marshall, disebut rasio stabilitas untuk mengalir dan dengan demikian mewakili perkiraan rasio beban terhadap deformasi di bawah kondisi khusus tes, dapat digunakan sebagai ukuran resistensi material terhadap deformasi permanen dilayanan. Tujuan dari penelitian ini adalah untuk menyelidiki kegunaan dari bahan limbah yang mengandung HDPE dalam HMA sebagai pengubah bitumen. Mempertimbangkan peran deterministik mereka dalam kinerja campuran aspal yang dimodifikasi polimer studi difokuskan pada efek pengubah (HDPE) konten, modifier - waktu pencampuran bitumen dan suhu pencampuran memperhatikan stabilitas, aliran, dan Marshall Hasil bagi

\section{METODE PENELITIAN}

Bahan dan prosedur desain eksperimental yang digunakan di Penelitian ini mengikuti. Bitumen yang digunakan adalah AC-20 aspal. Aspal ini menjadi standar standar tes laboratorium. Hasil tes ini dimasukkan pada tabel 1. Dalam penyelidikan ini, buang HDPE di bentuk bubuk digunakan sebagai pengubah. Gravitasi spesifik modifier diukur menjadi 0,935 g / $\mathrm{cm} 3$. Gradasinya HDPE disajikan pada tabel 2. Hancur batu kapur itu digunakan sebagai bahan agregat. Lalu lintas padat tipikal gradasi untuk aspal campuran panas (HMA), ditetapkan sebagai Tipe II dalam Spesifikasi Jalan Raya Negara Indonesia. Gradasi yang dipilih dan batas spesifikasi adalah ditunjukkan pada tabel 3. Beberapa sifat batu kapur hancur

Tabel 2: Gradasi polietilen densitas tingg

\begin{tabular}{lc}
\hline Sieve size & Percent passing \\
\hline No. $10(2 \mathrm{~mm})$ & 100 \\
No. $40(0.42 \mathrm{~mm})$ & 0 \\
\hline
\end{tabular}

Tabel 3: Gradasi yang digunakan dalam penelitian ini dan batas gradasi 


\begin{tabular}{lcc}
\hline Sieve size (in.) & Gradation limits & Used gradation \\
\hline $3 / 4$ & 100 & 100 \\
$1 / 2$ & $77-100$ & 87 \\
$3 / 8$ & $66-84$ & 74 \\
No. 4 & $46-66$ & 54 \\
No. 10 & $30-50$ & 35 \\
No. 40 & $12-28$ & 14 \\
No. 80 & $7-18$ & 9 \\
No. 200 & $4-10$ & 6 \\
\hline
\end{tabular}

Metode Uji Marshall digunakan untuk menentukan resistensi terhadap aliran plastik campuran bitumen yang disiapkan dengan atau tanpa aspal HDPE yang dimodifikasi. Awalnya, konten bitumen ibu ditemukan $4,5 \%$ (berat total mix) untuk campuran yang tidak dimodifikasi. Spesimen Marshall dibuat sesuai dengan ASTM D 1559. Mixer poros vertikal kecepatan disesuaikan dengan kapasitas 21 digunakan untuk mencampur HDPE dan bitumen. Suhu kontrol selama pencampuran dicapai dengan menggunakan termostat berjalan dengan termokopel yang melekat pada mixer. Itu mesin dioperasikan pada $200 \mathrm{rpm}$ untuk HDPE - campuran bitumen. Strategi pemanfaatan harus dibarengi dengan lingkungan. pertimbangan mental dan energi untuk menggunakan bahan yang tersedia paling efisien. Karena jumlah HDPE, bitumen - HDPE suhu pencampuran dan bitumen - waktu pencampuran HDPE merupakan bagian penting dalam menentukan kinerja HDPE Jika beton aspal diikat, ini dianggap sebagai faktor yang mempengaruhi kinerja beton aspal dalam desain percobaan. Pengikat yang digunakan dalam HMA disiapkan dengan pencampuran HDPE dalam 4-6 dan 8\% (dengan berat optimal konten bitumen) dan AC-20 pada suhu pencampuran.

Tabel 4: Beberapa sifat fisik agregat batu kapur yang dihancurkan

\begin{tabular}{ll}
\hline Frost & $0<12 \%$ \\
Los Angeles Abrasion Test & $22<35 \%$ \\
Flatness & cubic \\
Stripping (AC-5) & $60-65>50$ \\
Organic material & none \\
\hline
\end{tabular}

Tabel 5: Gravitasi spesifik agregat $(\mathrm{g} / \mathrm{cm} 3)$ 


\begin{tabular}{llc}
\hline Size fraction & $\begin{array}{l}\text { Apparent specific } \\
\text { gravity }\end{array}$ & $\begin{array}{l}\text { Bulk specific } \\
\text { gravity }\end{array}$ \\
\hline Coarse aggregate & 2713 & 2682 \\
Fine aggregate & 2729 & 2687 \\
Filler & 2730 & - \\
\hline
\end{tabular}

Tabel 6: Spesifikasi direktorat jenderal jalan raya Indonesia untuk memakai permukaan tentu saja mengalami volume lalu lintas yang tinggi

\begin{tabular}{ll}
\hline Properties of Marshall specimens & Specification limits \\
\hline Stability $(\mathrm{N})$ & $\min .9 \mathrm{kN}$ \\
Air voids (\%) & $3-5$ \\
Flow (mm) & $2-4$ \\
Voids of filled with asphalt cement $(\%)$ & $75-85$ \\
\hline
\end{tabular}

145-155 dan $165^{\circ} \mathrm{C}$ dan 5-15 dan 30 menit pencampuran waktu. Setelah mendapatkan aspal yang dimodifikasi HDPE, agregate dan bitumen yang dimodifikasi HDPE dipanaskan secara terpisah ke 165 dan $155^{\circ} \mathrm{C}$, masing - masing, dan kemudian dicampur dengan agregat dalam mixer mekanis. Campuran itu ditempatkan dalam cetakan Marshall dan dipadatkan dengan menerapkan 75 pukulan di setiap sisi spesimen pada $145 \mathrm{jC}$. Tercatat bahwa semua spesimen memiliki udara yang kira-kira sama rasio batal. Rasio kekosongan spesimen berada dalam kisaran dari spesimen 3,07-3,35\%. Dimensi standar sampel adalah 63,5 mm tinggi dan 101,5 $\mathrm{mm}$ diameter. Setelah dingin pada suhu kamar selama 1 hari dan kemudian dibiarkan dalam air pada 60 jC selama 30 menit, sampel diuji dengan alat Uji Marshall. Semua hasilnya diperoleh dari spesimen yang dipadatkan secara optimal konten bitumen dari setiap jenis campuran dan setiap hasil berasal dari rata-rata tiga spesimen uji. Untuk mengevaluasi sifat-sifat limbah beton aspal HDPE yang dimodifikasi spesimen, Spesifikasi Direktorat Jenderal Indonesia Jalan Raya untuk Permukaan Kasar Mengalami Volume Tinggi Lalu Lintas digunakan.

\section{HASIL DAN PEMBAHASAN}

\subsection{Stabilitas}

Gambar 1 menunjukkan variasi stabilitas dengan berbagai variasi bitumen dan limbah HDPE pencampuran suhu dan waktu. Ini menunjukkan bahwa stabilitas menurun dengan meningkatnya konsentrasi HDPE tenda untuk semua suhu pencampuran dan waktu pencampuran. Stabilitas campuran kontrol adalah $14 \mathrm{kN}$. Untuk HDPE 4\% dan 6\% campuran, 
stabilitas lebih tinggi daripada campuran kontrol. Efeknya dari waktu pencampuran lebih jelas pada pencampuran suhu $165{ }^{\circ} \mathrm{C}$. Stabilitas maksimum tercapai pada $4 \%$ HDPE, suhu pencampuran $165 \mathrm{jC}$ dan pencampuran 30 menit. Nilai stabilitas Marshall meningkat sebesar 50\% ketika 4\% HDPE diganti dengan AC-20. Penurunan stabilitas sementara peningkatan konten HDPE dapat dikaitkan dengan berkurang adhesi.

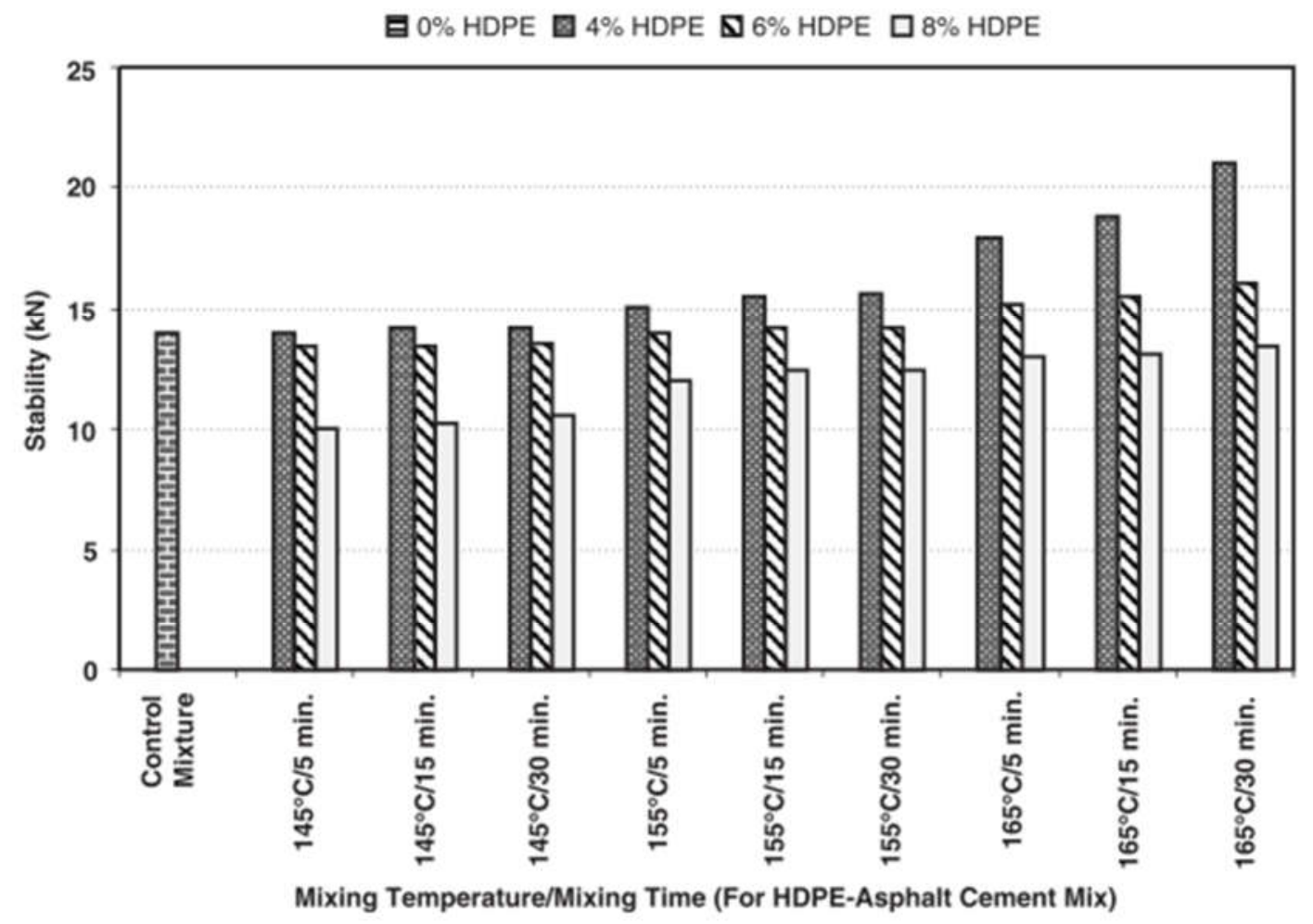

Gambar. 1. Suhu pencampuran / waktu pencampuran vs stabilitas

\subsection{Flow}

Ini terlihat dari gambar 2 bahwa aliran meningkat dengan meningkatnya konten HDPE. Flow adalah 3,8 mm untuk campuran kontrol. Meskipun aliran berkurang dengan meningkatnya suhu pencampuran dan waktu pencampuran, semua nilai aliran lebih tinggi dari mengontrol spesimen kecuali untuk binder yang disiapkan pada saat pencampuran suhu $165^{\circ} \mathrm{C}$, waktu pencampuran 30 menit dan mengandung HDPE 4\%. Ini mungkin menyiratkan peningkatan jumlah tersebut HDPE mempengaruhi gesekan interior campuran dalam cara negatif. Nilai aliran terkecil, 3,8 mm, adalah mencapai pada HDPE $4 \%$, suhu pencampuran $165{ }^{\circ} \mathrm{C}$ dan waktu pencampuran 30 menit. 


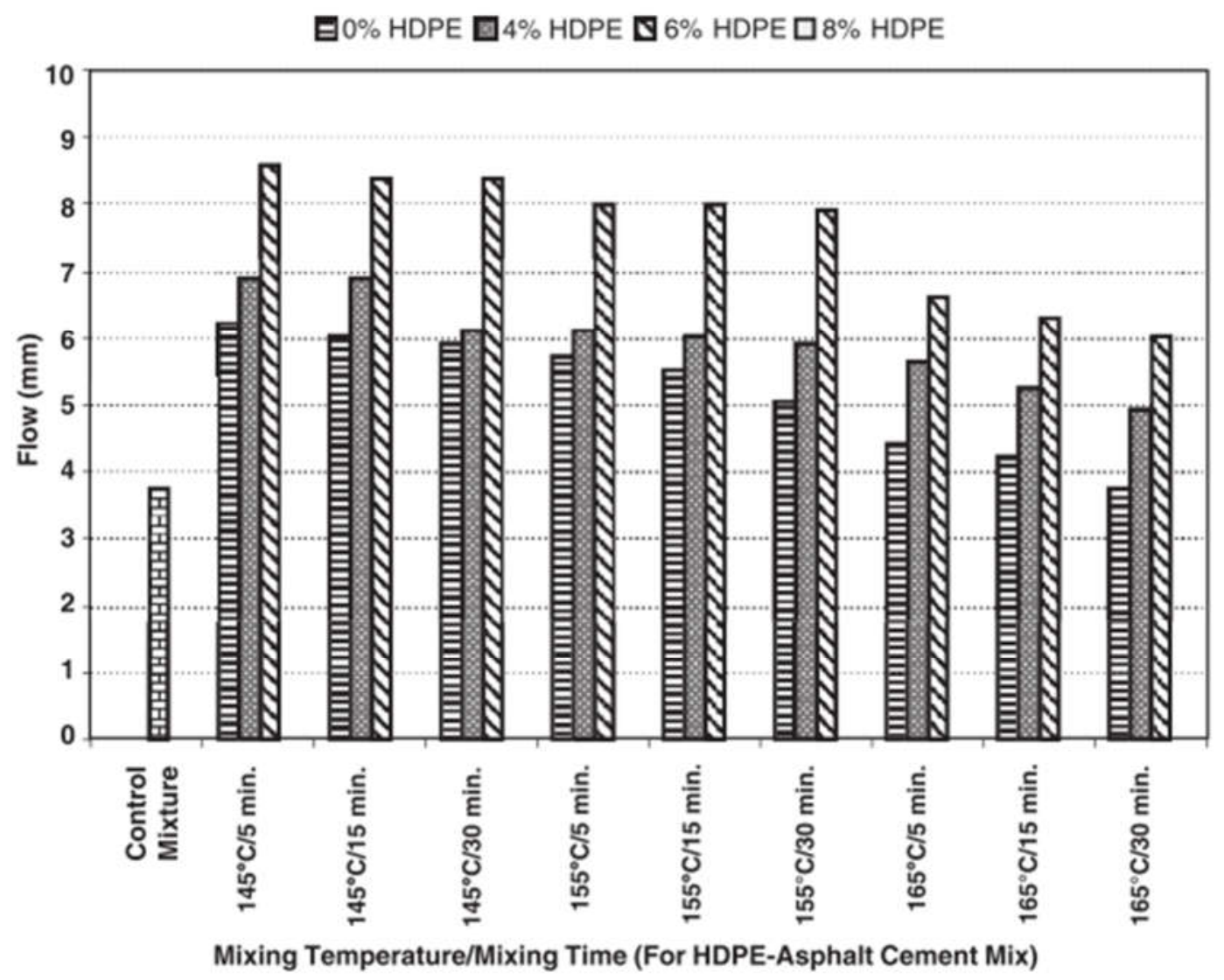

Gambar 2. Suhu pencampuran / waktu pencampuran vs Flow.

\subsection{Marshal Qutient (MQ)}

Karena Marshall Quotient (MQ) adalah indikator dari resistensi terhadap deformasi beton aspal Nilai MQ dihitung untuk mengevaluasi resistensi dari deformasi spesimen yang dimodifikasi HDPE. Nilai MQ yang lebih tinggi menunjukkan campuran yang lebih kaku dan, karenanya, mengindikasikan bahwa campuran tersebut kemungkinan lebih tahan. 


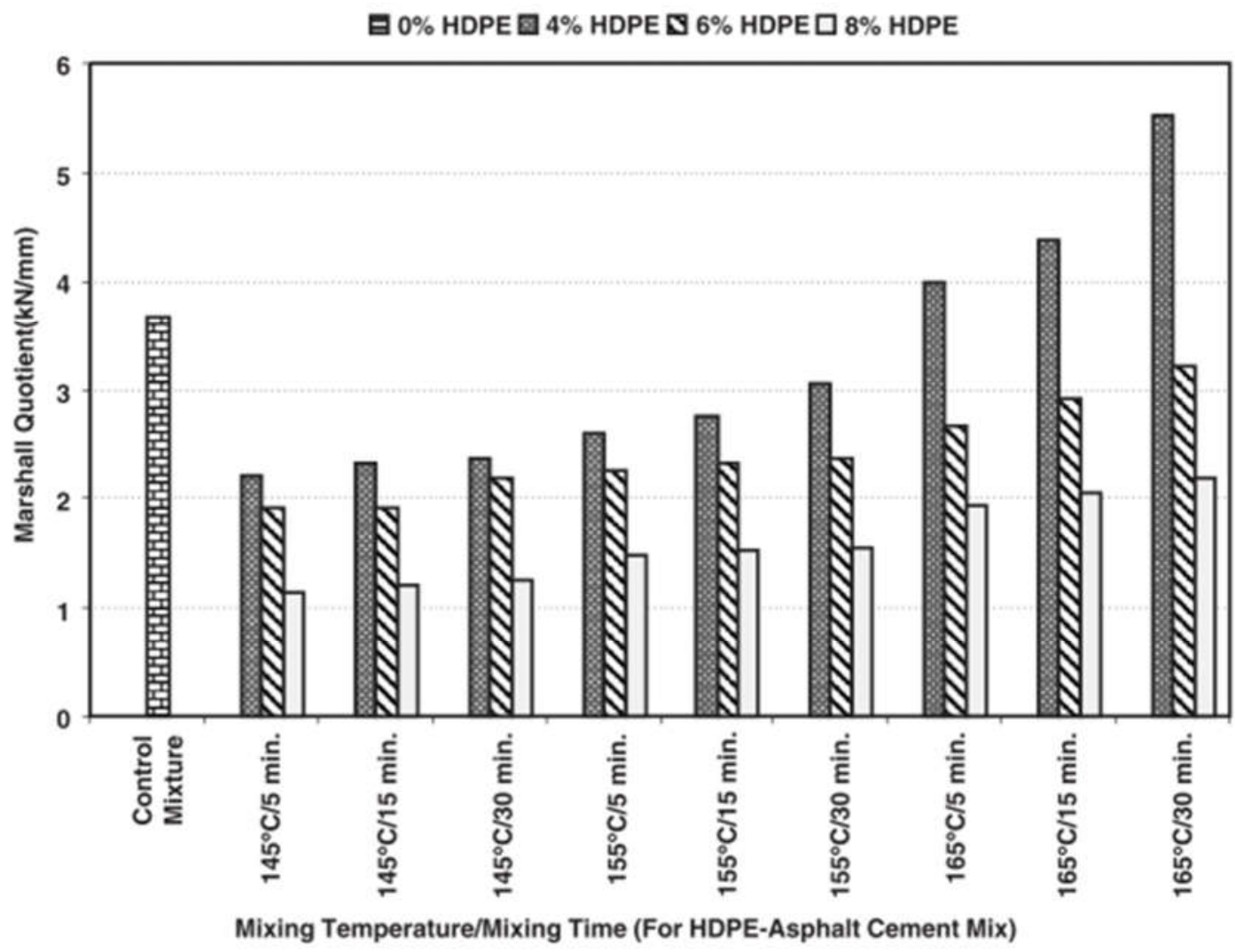

Gambar 3. Suhu pencampuran / waktu pencampuran vs. Marshall Quotient

Tabel 7:Perbandingan kontrol dan limbah beton aspal HDPE yang dimodifikasi

\begin{tabular}{lcll}
\hline & $\begin{array}{l}\text { Control } \\
\text { mixture }\end{array}$ & $\begin{array}{l}\text { Mixture with } \\
4 \% \text { HDPE }^{a}\end{array}$ & $\begin{array}{l}\text { Specification } \\
\text { limits }\end{array}$ \\
\hline Void ratio $(\%)$ & 3.32 & 3.07 & $3-5$ \\
VMA $(\%)$ & 12.78 & 12.57 & min. 14 \\
Voids filled with & 75 & 75.55 & $75-85$ \\
$\quad$ binder $(\%)$ & 14 & 21 & min. $9 \mathrm{kN}$ \\
Stability $(\mathrm{kN})$ & 3.8 & 3.8 & $2-4$ \\
Flow $(\mathrm{mm})$ & 3.68 & 5.53 & - \\
Marshall Quotient & & & \\
$\quad(\mathrm{kN} / \mathrm{mm})$ & & & \\
\hline
\end{tabular}

Spesimen memiliki MQ lebih tinggi dari pada campuran kontrol yang disiapkan dengan HDPE $4 \%$ pada suhu pencampuran $165^{\circ} \mathrm{C}$ dan 30 min periode pencampuran gambar 3. Spesimen di bawah suhu ruangan yang disebutkan di atas memberikan semua spesifikasi batas untuk parameter Desain Marshall. Limbah HDPE konten 4\% (berat konten aspal optimal), $165{ }^{\circ} \mathrm{C}$ suhu pencampuran dan waktu pencampuran 30 min memenuhi semua batas spesifikasi yang diberikan pada tabel 6. Hasil parameter dan nilai desain Marshall MQ untuk kontrol dan limbah aspal yang dimodifikasi HDPE campuran beton ditampilkan untuk tujuan perbandingan di tabel 7. 


\section{KESIMPULAN}

Dari temuan karya ini, berikut ini kesimpulan ditarik. Disimpulkan bahwa spesimen disiapkan dengan suhu pencampuran $165^{\circ} \mathrm{C}$ dan $30{ }^{\circ} \mathrm{C}$ waktu pencampuran untuk HDPE $4 \%$ memiliki stabilitas tertinggi dan aliran terkecil, dan juga Marshall Quotient tertinggi. peningkatan stabilitas menunjukkan bahwa campuran HDPE yang dimodifikasi jauh lebih kuat daripada campuran kontrol. Campuran ini sangat tahan terhadap deformasi permanen (rutting) di aspal beton. Meskipun nilai aliran HDPE dimodifikasi beton aspal sama dengan campuran kontrol, lebih tinggi nilai MQ diperoleh karena nilai stabilitas yang lebih tinggi. MQ meningkat 50\% dibandingkan dengan campuran kontrol. Itu artinya beton aspal yang memiliki nilai MQ lebih tinggi mengindikasikan tinggi

\section{DAFTAR PUSTAKA}

[1] AASHTO. 1990. Standard Specifications For Transportation Materials And Methods of Sampling and Testing. Part I. "Specifications". Fifteenth Edition. Washington,D.C

[2] AASHTO. 1990. Standard Specifications For Transportation Materials And Methods of Sampling and Testing. Part II. "Tests". Fifteenth Edition. Washington,D.C.

[3] ASTM D 1559-76 atau AASHTO T-245-90, Rancangan Campuran Berdasarkan Metode Marshall.

[4] April Gunarto, A. I. C. K. (2019). Penelitian Campuran Aspal Beton Dengan Menggunakan Filler Bunga Pinus. UKaRsT, 3(1), 37. https://doi.org/10.30737/ukarst.v3i1.351

[5] Candra, A. I., Mudjanarko, S. W., \& Limantara, A. D. (2017). Manajemen Data Lalu Lintas Kendaraan Berbasis Sistem Internet Cerdas Kadiri. Semnastek, 4(2), 1-2. Retrieved from jurnal.umj.ac.id/index.php/semnastek

[6] Departemen Pekerjaan Umum. 1987. Petunjuk Pelaksanaan Lapis Aspal Beton (Laston) Untuk Jalan Raya.

[7] Departemen Pekerjaan Umum. 1999. Pedoman Perencanaan Campuran Beraspal Panas Dengan Pendekatan Kepadatan Mutlak Jakarta: PT. Mediatama Saptakarya (PT. Medisa).

[8] Direktorat Jenderal Bina Marga Departemen Pekerjaan Umum Republik Indonesia. 2010. Spesifikasi Umum Divisi 6 hal 38

[9] Direktorat Jenderal Bina Marga Departemen Pekerjaan Umum Republik Indonesia. 2010. Spesifikasi Umum Divisi 6 Perkerasan Aspal

[10] Sukirman, Silvia. 1999. Dasar-dasar Perencanaan Geometrik Jalan. Jakarta. Granit.104 hal. Tenrisuki,Andi Tenriajeng. Seri Diktat Kuliah Rekayasa Jalan Raya Gunadarma. 207 hal.

[11] Muaya, G. S., Kaseke, O. H., \& Manoppo, M. R. (2015). Pengaruh Terendamnya Perkerasan Aspal oleh Air Laut yang Ditinjau terhadap Karakteristik Marshall. Jurnal Sipil Statik, 3(8).

[12] Edison, B. (2014). Karakteristik Campuran Aspal Panas (Asphalt Concrete-Binder Course) Menggunakan Aspal Polimer. Jurnal Aptek, 2(1), 60-71.

[13] SNI (1989). Tata Cara Pelaksanaan Lapis Aspal Beton (Laston) Untuk Jalan Raya. SNI 031737-1989.

[14] SNI (2008). Cara Uji Berat Jenis Dan Penyerapan Agregat Halus. SNI 1970 : 2008.

[15] SNI (2011). Cara Uji Berat Jenis Aspal. SK SNI 2441-2011. 
[16] SNI (2011). Cara Uji Penetrasi Aspal. SK SNI 2456-2011.

[17] SNI (2011). Pengujian Titik Lembek Aspal. SK SNI 2434-2011.

[18] SNI (2011). Pengujian Titik Nyala dan Titik Bakar Aspal. SK SNI 2433-2011. 